\title{
'El Niño' Effects and Biomass Endogeneity in a Harvest Function: The Chilean Jack Mackerel Fishery*
}

\author{
Julio Peña-Torres ${ }^{\mathrm{a} /}$
}

\author{
Claudio Agostini ${ }^{\mathrm{b} /}$
}

Sebastian Vergara ${ }^{\mathrm{c} /}$

Marzo 2005

\begin{abstract}
The main goal of this paper consists in estimating the input parameters of an annual harvest function for the Chilean jack mackerel stock; particularly, the effects of biomass on catch. One of the main problems faced is that the biomass variable is possibly endogenous, which would bias the estimators if the problem remains unsolved. Our empirical strategy consists in estimating a per vessel harvest function using panel data, which allows us to control for vessels' unobserved heterogeneity, and episodes of 'El Niño' phenomenon as valid instrumental variable for biomass, which allows us to control for the potential biomass endogeneity. This strategy produces consistent estimates of the biomass coefficient. The results, using a panel of industrial vessels operating in the central-southern region of Chile during the period 1985-2002, show that the endogeneity of the biomass variable biases upwardly the magnitude of its coefficient in a CobbDouglas harvest function. In the case of our data, the endogeneity bias even changes the sign of the catch-to-biomass elasticity. A first contribution of the paper is to address the endogeneity of biomass in a harvest function, an issue often underestimated in the empirical literature. A second contribution is related to 'El Niño' effects on the Chilean jack mackerel stock. The results show that an oceanic 'El Niño' episode not only has negative contemporaneous effects on jack mackerel biomass but also negative biomass effects lasting for at least two additional years.
\end{abstract}

Key words: 'El Niño' phenomenon; pelagic fisheries; Chilean jack mackerel; Instrumental variable estimation; marginal stock effects; endogenous biomass

a/ Corresponding author: J. Peña-Torres <ipena@uahurtado.cl> is Associate Professor at ILADESUniversidad Alberto Hurtado and Professorial Lecturer in Economics at Georgetown University. Mail address: Erasmo Escala 1835, Santiago, Chile.

b/ C. Agostini<agostini@uahurtado.cl> is Assistant Professor at ILADES-Universidad Alberto Hurtado and Professorial Lecturer in Economics at Georgetown University. Mail address: Erasmo Escala 1835, Santiago, Chile.

c/ S. Vergara < Sebastian.vergara@,cepal.org $>$ is Research Assistant at the Division of Production, Productivity and Management, Economic Commission for Latin America and the Caribbean (ECLAC), United Nations, Santiago, Chile. 


\section{Introduction}

This paper focuses in analysing the effects of fish stock changes on catch. In particular, it analyses the possible endogeneity of the biomass variable in a harvest function. The case analysed is the Chilean central-southern jack mackerel (Trachurus symmetricus murphyi) fishery, which is described in section 2.

To analyse the relationship between catch yields and stock levels is equivalent to studying the stock dependence of vessels' catch per unit of effort. A lower (higher) stock dependence of catch per unit of effort tends to increase (reduce) the risk of fishing collapse. A weak 'stock dependence' is another way of referring to a weak 'marginal stock effect' (Clark 1976). A weaker (stronger) 'marginal stock effect' tends to imply, ceteris paribus, a stronger (weaker) positive correlation between discount rates and stock depletion levels.

In the case of pelagic fish stocks, they usually provide for high catch yields. This is related to the fact that small pelagic fish dwell at relatively low depths and move about and migrate in large and dense schools. In the fishery here analysed this characteristic is reinforced by the high fishing productivity that is associated to the Humboldt Current. Given this particular combination of features, different pelagic fisheries around the world have experienced problems of fishing collapse. Examples in the $20^{\text {th }}$ century are the sardine fisheries in Japan during the early 1940s, the sardine fishery in California a decade later, the herring population in the North Sea at the end of the 1960s and early 1970s, and the collapse of the anchovy fishery in Peru during 1972-73.

Therefore, analysing the feature of catch's stock-dependence is particularly relevant for the case of pelagic fisheries. It is frequently assumed that the schooling behavior of pelagic fish implies unit harvesting costs tending to be stock independent (except for 'very low' stock levels; Clark 1982), which increases the stock's vulnerability to fishing effort. In the extreme case of no stock dependence, the literature speaks of 'pure' schooling behavior (Bjorndal 1988, 1989). In a more general case, pelagic fisheries have often been described as implying catches with 'weak' stock dependence (Clark 1982; Csirke 1988). The latter has been interpreted as implying a catch-tobiomass elasticity that is positive but lower than one (Hannesson 1983).

With respect to empirical evidence on these subjects, there are some studies that consider econometric estimations of harvesting functions for pelagic fisheries in the Northern hemisphere. Results with positive values are predominant for the catch to biomass elasticity, though they are usually lower than the unit value. This is the case of the results obtained for a herring fishery in the North Sea (Bjorndal \& Conrad 1987), as well as for the anchovy fishery in California 
(Opsomer \& Conrad 1994). Less conclusive results are obtained in Bjorndal et al. (1993), who study the Norwegian fleet that operates in the seal fishery facing the Newfoundland-Labrador peninsula. Other studies have performed econometric estimation of harvest functions for pelagic fish (North Sea herring fishery) by assuming total independence between harvest levels and fish abundance (Bjorndal 1988, 1989). All the studies cited in this paragraph consider Cobb-Douglas harvest functions and perform ordinary least squares (OLS) estimations.

Previous econometric studies about the Chilean central southern pelagic fishery (PeñaTorres et al. 2003, 2004) have obtained positive and statistically significant values for (average period) point estimates of the catch-to-biomass elasticity. However, these estimates have been obtained by performing OLS estimations, without implementing a very convincing solution to the issue of biomass endogeneity. ${ }^{1}$ The analysis in this paper explores new routes for tackling the issue of biomass endogeneity when estimating a harvesting function. Specifically, we estimate a harvest function for the Chilean central-southern jack mackerel fishery using environmental shocks (corresponding to the 'El Niño' phenomenon) as instrumental variables for fish biomass. In doing so, we explore the effects of 'El Niño' phenomenon on the jack mackerel biomass, about which few is known.

The paper is organised as follows. Section 2 describes the fishery under study. Section 3 presents basic assumptions in our modelling of the harvest function. Section 4 explains our empirical approach for estimation purposes, while section 5 describes the data used. Section 6 reports and discusses the estimation results. Finally, section 7 offers concluding remarks.

\section{The central-southern pelagic fishery}

This fishery runs along the central-southern coastline of Chile, starting at the port of San Antonio in central Chile and extending southwards to the Valdivia region, a distance of about $1000 \mathrm{~km}$, with fishing effort centered on the Talcahuano (VIII) region (Figure 1). ${ }^{2}$

The Chilean central-southern jack mackerel fishery is part of a large oceanic distribution of jack mackerel stocks in the southeast Pacific (Figure 1, area A). Following a 'colonization' process that began in the early 1970s, jack mackerel today extends into the southeast Pacific as far as $1000 \mathrm{~nm}$ off the coasts of Central Chile (along the Subtropical Convergence, around $40^{\circ} \mathrm{S}$, reaching New Zealand and Tasmanian waters) (Serra 1991; Elizarov et al. 1993).

The so-called Chilean jack mackerel stock, distributed within Chilean waters and in the adjacent high seas, reaching in some areas to about $110^{\circ} \mathrm{W}$, is believed to be a self-sustaining 
stock (Serra 1991). Evseenko (1987) suggested the existence of an oceanic stock, beyond $120^{\circ} \mathrm{W}$ and along the Subtropical Convergence reaching to New Zealand and Tasmanian waters, but it is as yet a pending question whether the oceanic stock is self-sustaining or needs inputs from the Chilean stock to persist. ${ }^{3}$

Off Chilean coasts, the jack mackerel is caught in four main fishing grounds (see Figure 1): a northern fishery, covering from the Chilean/Peruvian border $\left(18^{0} 20^{\prime} \mathrm{S}\right)$ up to the Antofagasta area; a north-center or Coquimbo fishery; a central-southern fishery which is off the Talcahuano region $\left(35^{0} \mathrm{~S}-38^{0} \mathrm{~S}\right)$ and extends southerly up to $43^{0}-46^{0} \mathrm{~S}$; and an international fishery in high-seas adjacent to the Chilean EEZ. Since the mid 1980s, a predominant proportion of Chilean jack mackerel landings have been caught at the central-southern fishery. During the year 2004, landings obtained at the Talcahuano fishery represented 82 per cent of Chilean total commercial landings of jack mackerel.

Figure 1

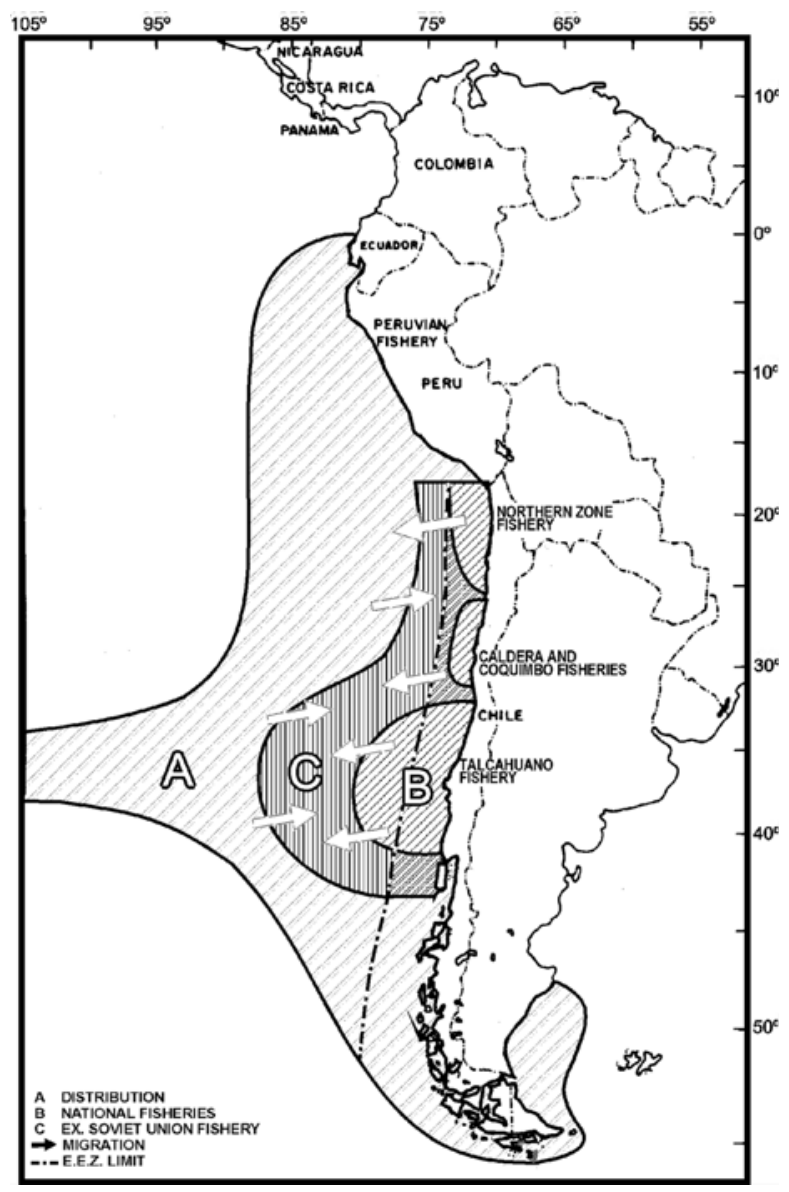


Along its history, Chilean owned purse seiners have mostly exploited this fishery. However, during the 1980s a fleet composed of vessels from Poland, Cuba and Russia fished jack mackerel in the high seas off Central Chile (as well as in other high seas areas of the Southeast Pacific). ${ }^{4}$

Industrial fishing is concentrated on pelagic species, primarily destined for the fishmeal industry. Although in its early industrial development the main species harvested in this fishery were anchovy (Engraulis ringens) and sardine (Clupea bentincki), since the beginning of the 1980s jack mackerel has become the dominant species for industrial vessels. Industrial landings of jack mackerel represented 82 per cent of total industrial landings during the period 1985-2002 (Table 1). ${ }^{5}$ The Central-Southern pelagic fishery currently generates between US\$200-250 million/year, in terms of export value and national sales. This value represents around 20 per cent of yearly exported values by the Chilean extractive fishing industry.

The early 1980s coincide with the starting of a phase of intense investment (see Table 1). From 1980 to 1985 the number of industrial vessels doubled, while the fleet's hold capacity quadrupled. In the following decade the aggregate hold capacity again increased four times. This occurred at a moment when larger vessels began to increase their participation in the fleet (see Table 2). Aggregate annual haul of the fleet increased 6.5 times during the 1985-95 period. Annual haul is defined as the sum of the hold capacity for all operating industrial vessels, weighted by the respective hours the vessels spend fishing during each year. The concept of haul proxies the level of use assigned to the available aggregate fishing capacity.

The growth in annual harvest continued uninterrupted until 1994-95 and has since declined. The decline was accelerated by the 'El Niño' phenomenon that began in 1997 and lasted until late 1999. Catches of the three main species at year 2002 had declined to less than half the 1994-95 peak; jack mackerel catches have also declined by more than half.

The investment boom of the 1980s began under free access conditions, which prevailed from 1978 to 1986. From that point on, access regulations went into effect that 'froze' the fleet's hold capacity to the limits it had in 1986. However, legal loopholes remained, allowing for further expansions of the fleet's fishing capacity (column 3 of Table 1). For example, substituting two or more small vessels by a larger one was allowed if the resulting hold capacity remained fixed. In practice, this allowed the entry of vessels with greater fishing capacity. Additional fishing licenses were also given to new vessels for starting fishing operations at the $\mathrm{V}$ and $\mathrm{X}$ regions. Therefore, access restrictions were introduced on a gradual basis at the different fishing grounds 
of the central-southern fishery. As a result, the total number of operating ships kept increasing up to the early 1990s (Table 1, column 2).

Table 1: Central-Southern Pelagic Fishery (from V to X region)

\begin{tabular}{|c|c|c|c|c|c|c|c|}
\hline \multirow[b]{2}{*}{ Year } & \multicolumn{3}{|c|}{ Industrial Fleet } & \multicolumn{2}{|c|}{$\begin{array}{l}\text { Industrial fleet's Landings } \\
\text { (10 tons })\end{array}$} & \multicolumn{2}{|c|}{ Yearly Average Biomass ( $10^{6}$ tons $)$} \\
\hline & $\begin{array}{c}\text { Fishing } \\
\text { Effort } \\
\text { (index) } \\
(1)\end{array}$ & $\begin{array}{c}\text { Number of } \\
\text { vessels } \\
\text { (2) }\end{array}$ & $\begin{array}{c}\text { Total Hold } \\
\text { Capacity } \\
\left(10^{3} \mathrm{~m}^{3}\right) \\
(3)\end{array}$ & $\begin{array}{c}\text { Three main } \\
\text { species } \\
\text { (4) }\end{array}$ & $\begin{array}{c}\text { Jack } \\
\text { Mackerel } \\
\text { (5) }\end{array}$ & $\begin{array}{c}\text { Three Main } \\
\text { Species } \\
\text { (V-X regions) } \\
\text { (6) }\end{array}$ & $\begin{array}{c}\text { Jack Mackerel } \\
\text { (national level) } \\
\text { (7) }\end{array}$ \\
\hline 1975 & & 37 & 4.3 & & & & 2.23 \\
\hline 1980 & & 47 & 6.3 & & & & 7.18 \\
\hline 1985 & 100.0 & 97 & 28.4 & 0.953 & 0.854 & & 15.19 \\
\hline 1986 & 143.6 & 93 & 29.9 & 1.128 & 1.051 & & 15.90 \\
\hline 1987 & 156.5 & 93 & 33.2 & 1.528 & 1.341 & & 15.85 \\
\hline 1988 & 191.0 & 105 & 40.4 & 1.705 & 1.439 & & 15.19 \\
\hline 1989 & 236.4 & 108 & 50.5 & 2.001 & 1.677 & & 16.08 \\
\hline 1990 & 307.7 & 145 & 67.9 & 2.093 & 1.860 & 16.00 & 15.45 \\
\hline 1991 & 362.9 & 179 & 84.4 & 2.870 & 2.331 & 15.60 & 13.71 \\
\hline 1992 & 424.7 & 176 & 87.1 & 2.882 & 2.472 & 12.50 & 10.86 \\
\hline 1993 & 462.2 & 171 & 95.5 & 2.618 & 2.392 & 12.08 & 10.25 \\
\hline 1994 & 572.3 & 168 & 103.9 & 3.575 & 3.254 & 11.16 & 9.49 \\
\hline 1995 & 674.7 & 179 & 117.8 & 4.021 & 3.732 & 9.46 & 8.03 \\
\hline 1996 & 636.8 & 159 & 113.6 & 3.401 & 2.805 & 10.15 & 7.32 \\
\hline 1997 & 741.9 & 177 & 133.3 & 2.947 & 2.533 & 9.84 & 6.83 \\
\hline 1998 & 610.9 & 163 & 131.0 & 2.079 & 1.465 & 10.07 & 7.08 \\
\hline 1999 & 595.3 & 161 & 131.1 & 2.550 & 1.082 & 8.94 & 6.71 \\
\hline 2000 & 447.3 & 148 & 125.9 & 1.802 & 1.063 & 8.93 & 7.05 \\
\hline 2001 & 310.6 & 107 & 102.3 & 1.548 & 1.215 & 10.29 & 6.61 \\
\hline 2002 & 370.8 & 65 & 70.3 & 1.400 & 1.142 & 9.94 & 6.48 \\
\hline
\end{tabular}

(1) Total annual haul of industrial fleet (annual fishing hours multiplied by hold capacity), including all vessels operating at each year t; (2) Total number of operating industrial vessels at each year; (3) Industrial fleet's total hold capacity (thousand of $\mathrm{m}^{3}$ ); (4) Industrial fleet's annual landings (three main species: common sardine, anchovy and jack mackerel); (6) and (7): Yearly average biomass (recruits and older age cohorts, in million of tons) estimated by the Chilean Fisheries Research Institute (IFOP). Column (6) refers to estimates for the CentralSouthern zone, while column (7) refers to estimates at the national level (within Chile's EEZ).

Sources: IFOP and Sernapesca's Annual Fisheries Annals.

The number of operating boats started to decline since 1998. This result was affected by the systematic use of temporary fishing closures between November 1997 and December 2000. The fishing closures were part of a broader regulatory scheme called 'Research Fishing Trips' (RFT) Program, which in the central-southern zone was exclusively concentrated on the jack mackerel fishery. Under the RFT Program, and when fishing effort was permitted within a given year, the fishery regulator and boat owners jointly decided which particular vessels would be allowed to operate at the jack mackerel fishery. Each of the chosen vessels had to prospect a specific marine area in order to collect catch sampling information to be used for fish stock 
assessment purposes. ${ }^{6}$ Resulting catches could then be commercialised by boat owners, subject to complying with ex-ante defined vessel catch quotas. In practice, this regulatory scheme corresponded with a de facto individual vessel (non-transferable) catch quota system (PeñaTorres 1997, 2002). Key reasons for starting with this regulatory scheme were, on the one hand, quickly deteriorating patterns at that time in catch yields and biomass estimates and, on the other, a series of binding conditions which significantly restricted the use of other regulatory instruments by the fisheries regulator.

Table 2: Number of Operating Vessels at the Central-Southern Pelagic Fishery

\begin{tabular}{ccccc}
\multicolumn{5}{c}{ (Estimation sample) } \\
\hline Year & $\begin{array}{c}\text { Small } \\
\left(80-300 \mathrm{~m}^{3}\right)\end{array}$ & $\begin{array}{c}\text { Medium } \\
\left(301-800 \mathrm{~m}^{3}\right)\end{array}$ & $\begin{array}{c}\text { Large } \\
\left(>801 \mathrm{~m}^{3}\right)\end{array}$ & Total \\
\hline 1985 & 52 & 38 & 2 & 92 \\
1986 & 47 & 44 & 2 & 93 \\
1987 & 42 & 49 & 2 & 93 \\
1988 & 40 & 62 & 3 & 105 \\
1989 & 31 & 66 & 11 & 108 \\
1990 & 50 & 74 & 21 & 145 \\
1991 & 55 & 101 & 23 & 179 \\
1992 & 54 & 94 & 28 & 176 \\
1993 & 40 & 90 & 41 & 171 \\
1994 & 30 & 87 & 51 & 168 \\
1995 & 27 & 92 & 60 & 179 \\
1996 & 22 & 73 & 64 & 159 \\
1997 & 22 & 79 & 76 & 177 \\
1998 & 16 & 70 & 77 & 163 \\
1999 & 14 & 70 & 77 & 161 \\
2000 & 9 & 63 & 76 & 148 \\
2001 & 4 & 34 & 68 & 106 \\
2002 & 2 & 10 & 53 & 65 \\
\hline Total vessels & \multicolumn{4}{l}{} \\
\hline *: This total corresponds to number of different vessels that fished for at least one year during 1985-2002. \\
Source: Authors elaboration based on IFOP data.
\end{tabular}

As a parallel development, towards the end of year 2000 a protracted process of political negotiations finally succeeded in enacting important amendments to the Chilean Fisheries Law (Peña-Torres 2002). The resulting new Fisheries Law (\#19 713) formally introduced, since February 2001, the use of individual catch quotas into the main industrial fisheries of Chile, including the case under analysis.

Annual Total Allowable Catch (TAC) assigned to industrial fleets (for each fishery unit') were divided into individual catch quotas (per boat owner), defined in tons. The initial quota allocations were given free of charge and had validity until December 2002. A new legal reform (Fisheries Law \#19 849, December 2002) then extended the validity of the individual quota 
system until year 2012. The assigned catch quotas 'per se' cannot be sold to another fisherman. The quota right is legally linked in an indissoluble manner to vessel ownership. Hence, transferability of quota ownership can only occur by means of transferring vessel ownership. However, operational transferability also prevails in the sense that different boat owners can associate among themselves, with the exclusive purpose of performing fishing operations, in order to decide on which specific vessels they will jointly use for fishing the quotas assigned to them.

The introduction of individual catch quotas into the central-southern fishery quickly produced significant operational adjustments. The number of operating vessels declined rapidly and significantly (column 2, Table 1$){ }^{8}$ a similar trend can be observed in terms of the total hold capacity that was being mobilised by the industrial fleet in operation.

\section{Modelling the harvest function}

Our main interest consists in estimating the parameters of the harvest function for jack mackerel and, particularly, the effects of biomass on catch. For this purpose, we need to analyse, firstly, the possible endogeneity of the biomass variable to be used as control for changes in fish stock availability; and secondly, if this endogeneity problem proved to be relevant for the data under analysis, to discuss which biases could be introduced into the estimates of the catch-to-biomass coefficient.

Given these priorities, we choose a simple and parsimonious functional form for estimating the harvesting technology. Firstly, we consider a Cobb-Douglas functional form which by construction supposes that catch-input elasticities correspond to constant values, i.e. they are independent from the scale of fishing operations or the particular level of fish stock scarcity. ${ }^{9}$

Secondly, we measure harvest output by focusing exclusively on jack mackerel landings, which is the dominant caught species all along the period studied (on average representing about 90 per cent of per vessel total landings). A key motivation for following this strategy is due to data availability regarding good (statistical) quality as well as lengthy time series of biomass estimates for jack mackerel. Biomass estimates for the other main species caught at this fishery are only available on shorter time series. Moreover, expert assessments about the statistical quality of biomass estimates for the other main species are also less consensual.

Given our focusing on the catch-to-biomass coefficient, by estimating a single-species harvest function we also reduce risks of misspecification which could result from multi-species 
modelling; particularly in fishery contexts where inter-species biological interactions are still not clearly understood, which is the case of the fishery analysed. Our estimations consider a per-vessel harvesting function of the following general type:

$$
H_{i t}=f\left(E_{i t}, B_{t}, R_{t}, \alpha_{i}, \varepsilon_{i t} ; \beta\right)
$$

where $H_{i t}$ denotes annual tonnage harvested by vessel i in year t, $E_{i t}$ is vessel i's use of variable inputs ('fishing effort'), $B_{t}$ is fish stocks' availability, $R_{t}$ a dummy variable for regulatory shocks, $\alpha_{i}$ is a control for vessel-idiosyncratic as well as time invariant features (denoted in the econometric literature as 'unobserved heterogeneity') which affect vessel catch yields per unit of variable fishing effort, $\varepsilon_{i t}$ is a residual term which encapsulates random (natural and man-originated) events affecting the harvesting success of vessel $i$ in year $t$, and $\beta$ represents a vector of parameters to be estimated.

The strategy of collapsing variable input choices into a single variable has well-established roots in fishery economics, resting on the plausible assumption that input ratios tend to be relatively fixed in fishing operations (for short- and medium-term decisions). $E_{i t}$ is expected to be positively associated with $H_{i t}$. However, per vessel harvesting is also conditioned by fixed investment in vessel's fishing capacity. This is a multi-attribute variable. Searching technology (sonar, airplane's support), engine power, fishing gears, storage capacity, and captain's idiosyncratic knowledge are some of the fixed factors contributing to explain differences in vessels' catch success. Our sample does not contain enough information to explicitly consider in detail all these attributes. However, one of the main advantages of using panel data is that allows us to control for all the unobserved effects that are specific to each vessel.

Our empirical strategy consists in estimating a per vessel harvest function using panel data, which allows us to control for the unobserved heterogeneity of the vessels and instrumental variables, which allows us to control for the potential endogeneity of the biomass.

\section{Empirical approach}

One of the main problems we faced in the estimation of the harvest function is that the biomass variable is probably endogenous, which would bias the estimators if the problem is not solved. There are two reasons why the biomass could be endogenous in a harvest function. The first one is behavioral: catch affects biomass in a negative way, as higher catch volumes reduce fish biomass. The second one is statistical. Our biomass variable is calculated by the Chilean Institute for Fisheries Research (IFOP) ${ }^{10}$ using Virtual Population Analysis. As we explain later, this 
methodology is based on the use of catch sampling data and therefore, by construction, the biomass estimates depend on catch volume as well as catch's age structure.

A feasible solution for the endogeneity problem is the use of instrumental variables. For this purpose we need to find a variable that is highly correlated with biomass and not correlated with the error term in the harvest function. Here we refer to partial correlation, i.e. a correlation between the instrument and the biomass, after all the other exogenous variables in the model are controlled for.

We perform instrumental variable estimation of the harvest function by using an oceanic measure of 'El Niño' phenomenon as a valid instrument for biomass. Later on we will discuss about the validity of this assumption, given the particular measurement we use for instrumentalising the changes in biomass.

We consider an oceanic measure of the 'El Niño' phenomenon because of migratory patterns of the jack mackerel stock. Between August and February each year, corresponding to the spawning season of this species, the spawning stock migrates deep into the Southeast Pacific. Although the spawning stock during this period achieves a wide North-South distribution, it has been reported (Cubillos 2003) that the main spawning area concentrates in front of the Chilean central-southern coastline, from 200 up to $1200 \mathrm{~nm}$. Eggs and larvae remain in these open seas areas until achieving juvenile status. Then juveniles start a migratory pattern travelling from West to East, entering the Chilean EEZ by its northern border. Here they first feed and grow and then start to migrate towards southern parts of the Chilean EEZ. Once the fishes achieve sexual maturity, at 2-3 years of age, the migratory pattern of the spawning stock is restarted.

As we explain in the next section, the variable biomass is measured with error. The effect of this measurement error, in the estimation of the harvest function, is to bias the coefficient of biomass towards zero (attenuation bias) and the coefficients of the other variables in unknown directions (Imbens and Hyslop 2001). The use of instrumental variables for the biomass allows us to solve this problem too.

Our empirical approach then consists in estimating the harvest function with panel data and using episodes of 'El Niño' phenomenon as instrumental variables for biomass. This strategy produces consistent estimates of the catch-to-biomass elasticity. 


\section{Data}

Our sample consists of a panel of industrial vessels operating in the central-southern region of Chile during the 1985-2002 period. There are 283 vessels in the sample, but the panel is unbalanced and the average number of observations per vessel is 7.9, with a minimum of 1 and a maximum of 18. The data on the industrial fleet operation was obtained from IFOP. It includes per vessel annual data on: landed tonnage (different species); hold capacity (measured in $\mathrm{m}^{3}$ ); annual operating hours off shore and vessel construction year.

In addition, we also obtained IFOP official estimates of jack mackerel's annual biomasses, covering the period 1975-2003. We use this variable to control for the fish stock level in each year t. The biomass variable aggregates different age cohorts (adding them up in terms of weight) of a given fish stock, measuring the resulting biomass in tons. For annual estimation of jack mackerel biomass, IFOP uses Virtual Population Analysis (VPA) adjusted by an ADAPT procedure which uses complementary information coming from hydro-acoustic surveys (Quinn \& Deriso 1999, 352-33; Serra \& Canales 2002). The VPA method estimates the age distribution of a fish population on the basis of historical information on harvest age composition. Through backward extrapolation of the fish abundance (number of fish by cohort), together with assumptions on natural mortality and harvest rates, the population age distribution is estimated. This distribution is subsequently adjusted by cohort average weights, from which the biomass estimations are finally derived. Therefore, by construction the biomass estimates depend on catch volume as well as the catch's age structure.

Table 3 shows the summary statistics of the data. Per vessel catch (denoted by 'Catch') is

measured by the annual landings of jack mackerel for each vessel (measured in tons). ${ }^{11}$ During the 1985-97 period, i.e. before the starting of fishing ban regulations in this fishery, jack mackerel represented on average nearly 90 per cent of total industrial landings in the central-southern fishery. Consistently, our measure of fish stock availability focuses exclusively on biomass estimates for jack mackerel.

In practice, however, the fleet under analysis performs multi-species harvesting. Apart from the three main species caught, there are other species which on average have minor participation in annual industrial landings at this fishery. Table 4 shows the three main species' average shares in total annual landings per industrial vessel. Considering years in which there were no direct regulations on fishing effort (i.e., excluding the 1998-2000 period when the RFT Program was in operation $)^{12}$, ships in the large size $\left(\geq 801 \mathrm{~m}^{3}\right)$ category clearly specialize in fishing jack mackerel. This species also has a dominant proportion in the annual catch of vessels 
belonging to the $301-800 \mathrm{~m}^{3}$ size category. A key reason for this is that vessel's maneuvering capacity and search capabilities play a crucial role in finding high-yield fishing grounds for catching jack mackerel. By contrast, smaller ships $\left(80-300 \mathrm{~m}^{3}\right)$ tend to specialise on coastal fishing, operating in areas where sardine and anchovies are the predominant species. Hence, the latter species represent a higher proportion of total landings for vessels belonging to the $80-300 \mathrm{~m}^{3}$ size category.

Table 3: Data Summary

(estimation sample)

\begin{tabular}{l|ccccc}
\hline Variable & $N$ & Mean & Std. Desv. & Minimum & Maximum \\
\hline Catch (tons.) & 2,229 & $14,662.39$ & $14,102.2$ & 4.0 & $71,912.5$ \\
Biomass (tons.) & 18 & $10,783,552$ & 933,148 & $6,417,076$ & $16,100,000$ \\
Effort (hours) & 2,229 & $2,847.2$ & $1,534.3$ & 6.98 & $6,049.3$ \\
Vessel Age (years) & 2,229 & 17.9 & 11.3 & 1 & 60 \\
Research98 & 18 & 0.036 & 0.187 & 0 & 1 \\
Research99 & 18 & 0.054 & 0.226 & 0 & 1 \\
Research00 & 18 & 0.032 & 0.177 & 0 & 1 \\
Nino1 & 18 & 0.61 & 0.5 & 0 & 1 \\
\hline
\end{tabular}

The variable used for capturing the effects of fishing effort (denoted by 'Effort') is the annual number of total hours a vessel is off shore. It is a measure of actual fishing effort, including travelling time to the areas where the vessel fishes. This variable aims at proxying variable input use. Given the data available, we do not know the proportions of annual fishing efforts which are devoted to fishing different species. ${ }^{13}$ Our measure of fishing effort covers all species caught. Hence, the latter feature does constrain the interpretations that can be given to estimations of the catch-to-effort elasticity.

The variable biomass is the annual average biomass of jack mackerel within Chilean waters $^{14}$, which considers a larger area than just the central-southern part of the country where our sample of vessels was actually fishing. Therefore, the variable biomass is measured with error for the purpose of estimating a harvesting function in the central-southern region of Chile.

Vessel age (denoted by 'Age') is measured in years and it is calculated as the difference between the current year and the construction year of each vessel. This variable controls for possible technological obsolescence and accumulated learning by doing effects. 
Table 4: Main species shares (yearly average) in total annual landing per vessel (industrial fleet, period 1985-2002)

\begin{tabular}{|c|c|c|c|c|c|c|}
\hline \multirow[b]{2}{*}{$\begin{array}{l}\text { Vessel size } \\
\text { category }\left(\mathrm{m}^{3}\right) \text { : }\end{array}$} & \multicolumn{2}{|c|}{$\begin{array}{c}(1) \\
\text { Jack mackerel }\end{array}$} & \multicolumn{2}{|c|}{$\begin{array}{c}(2) \\
\text { Common sardine }\end{array}$} & \multicolumn{2}{|c|}{$\begin{array}{c}\text { (3) } \\
\text { Anchovy }\end{array}$} \\
\hline & $\begin{array}{l}1998- \\
2000 \\
\end{array}$ & $\begin{array}{c}\text { Remaining } \\
\text { years in period } \\
1985-2002\end{array}$ & $\begin{array}{l}1998- \\
2000 \\
\end{array}$ & $\begin{array}{c}\text { Remaining } \\
\text { years in period } \\
1985-2002\end{array}$ & $\begin{array}{l}1998- \\
2000 \\
\end{array}$ & $\begin{array}{c}\text { Remaining } \\
\text { years in period } \\
1985-2002\end{array}$ \\
\hline \multicolumn{7}{|l|}{ 80-300: } \\
\hline Yearly Avg. & 0.05 & 0.39 & 0.46 & 0.30 & 0.47 & 0.26 \\
\hline St. Dv. & 0.06 & 0.31 & 0.24 & 0.26 & 0.29 & 0.23 \\
\hline \multicolumn{7}{|l|}{ 301-800: } \\
\hline Yearly Avg. & 0.23 & 0.73 & 0.38 & 0.10 & 0.34 & 0.09 \\
\hline St. Dv. & 0.12 & 0.26 & 0.12 & 0.15 & 0.11 & 0.13 \\
\hline \multicolumn{7}{|l|}{$\geq 801:$} \\
\hline Yearly Avg. & 0.71 & 0.87 & 0.06 & 0.01 & 0.09 & 0.01 \\
\hline St. Dv. & 0.11 & 0.09 & 0.05 & 0.03 & 0.08 & 0.04 \\
\hline
\end{tabular}

Notes:

(a) The notation ' 0.71 ' means $71 \%$ of yearly average total landings per vessel, within a given vessel-size category; Avg. means average; 'St. Dv.' means standard deviation.

(b) Shares are calculated on the basis of average annual landings (species composition) per vessel, for the following vessel size categories: (P1) 80-300 $\mathrm{m}^{3}$; (P2) 301-800 $\mathrm{m}^{3}$; (P3) $\geq 801 \mathrm{~m}^{3}$.

With the purpose of controlling for important regulatory changes occurring during the period of analysis, we consider two sets of dummy variables. Firstly, to control for the operation of the 'Research Fishing Trips' (RFT) Program, which was exclusively applied during the 19982000 period to jack mackerel catches in the central-southern pelagic fishery, we include dummy variables for 1998, 1999 and 2000 (denoted by 'Research98' and so on; see Table 5-A). The number of vessels involved in research fishing trips was 83 in 1998, 127 in 1999 and 74 in 2000. Overall, a total of 144 different industrial vessels made at least one research fishing trip over the 1998-2000 period.

Secondly, since 2001 the government introduced individual fishing quotas for the three main species caught at the central-southern pelagic fishery. This meant that for the first time TACs were formally introduced into this fishery. ${ }^{15}$ To control for the effects of the quota system we included dummy variables for the years 2001 and 2002. The variables D2001 and D2002 are equal to one for the year 2001 and 2002 respectively, and zero otherwise.

As it was explained before, we used environmental shocks, corresponding to an oceanic measure of 'El Niño' episodes, to identify the effect of changes in biomass levels upon per vessel catch. Based on the definition used by the National Oceanic and Atmospheric Administration 
(NOAA, USA), an oceanic episode of 'El Niño' occurs when the Oceanic 'El Niño' Index (ONI) increases by at least $0.5 \mathrm{C}^{\circ}$ above its historical level. ONI is a 3 month moving average of deviations in the sea surface temperature, relative to an historical level defined by the yearly average sea surface temperature for the period 1971-2000. ${ }^{16}$ The variable Niño $1_{t}$ is then a dummy variable equal to one if there occurs an 'El Niño' episode during year t (i.e., if there is at least one 3 -months average, within year $\mathrm{t}$, in which the $\mathrm{ONI}$ is at least $0.5 \mathrm{C}^{\circ}$ above its historical level) and zero otherwise.

In our estimations we also constructed and tested other variables for measuring 'El Niño' phenomenon. We constructed a Niño2 variable with the same dichotomic definition than Niño1, but now calculating its value by only considering 3-month moving averages corresponding to the spawning season (from October to February each year) of the jack mackerel stock. We also tested another variable which was aimed at controlling for the persistence (as well as the intensity) of 'El Niño' phenomenon. It was defined as equivalent to the number of 3-month moving averages, within each year $\mathrm{t}$, with ONI values equal to or greater than $+0.5 \mathrm{C}^{\circ}$. From all these measures for 'El Niño' phenomenon, Niño1 was the only one which consistently showed clear statistical significance and strong robustness in its sign of impact upon jack mackerel biomass. Therefore, we report here only the estimations obtained when using the Niñol variable.

Finally, to control for other time effects which might have a monotonic influence upon vessel catch yields and which are not dependent on vessel-idiosyncratic conditions, we also include a trend variable. This variable might capture general technological innovations or changes in fishing productivity over time.

\section{Results}

Table 5-A shows the fixed effects estimation of the following per vessel harvest function (all the variables, except the time trend $(T)$ and dummy variables $(D$ and $R)$, are in logs):

$$
\begin{aligned}
\text { Catch }_{i t}= & \beta_{0}+\beta_{1} \text { Biomass }_{t}+\beta_{2} \text { Effort }_{i t}+\beta_{3} \text { Age }_{i t}+\beta_{4} T_{t}+\sum_{j=1998}^{2000} \beta_{j} R_{j}+\sum_{j=2000}^{2001} \beta_{j} D_{j} \\
& +\sum_{j=1998}^{2000} \beta_{j} R_{j} \cdot \text { Effort }_{i t}+\alpha_{i}+\varepsilon_{i t}
\end{aligned}
$$


where the $\beta s$ denote the coefficients to be estimated, $\alpha_{i}$ are the fixed effects, $T$ is a trend variable, $R s$ here denote the dummies associated to the RFT Program, $D s$ are the dummies associated to the individual catch quota regulation and $\varepsilon_{i t}$ denotes the residual estimation errors.

Model (1) in the Table 5-A was estimated using Ordinary Least Squares (OLS) just for comparisons to Models (2) through (4), which were estimated using Instrumental Variables. The instrumental variables estimation is based on a two stage least squares estimation. The first stage is a regression of Biomass on all the exogenous variables of the model plus the instrument. The second stage regression consists of estimating equation (2), but replacing the variable Biomass by the fitted values of Biomass from the first stage regression. The standard errors for all models were obtained using the robust asymptotic variance matrix estimator proposed by Arellano (1987). This estimator is valid in the presence of heteroskedasticity or serial correlation if $\mathrm{T}$ (number of time periods) is smaller than $\mathrm{N}$ (number of cross-sectional units), which is the case in our sample.

The main advantage of using fixed effects estimation is that the fixed effects capture all the unobserved fixed factors per vessel that may affect catch yields: search technologies, engine horse power, fishing gear, and fishing experience of the captain and the crew, supposing that all these factors remain fixed over the studied period. The fixed effects specification was confirmed by a Hausman test, which rejected the alternative random effects specification. The implication of this result is that the use of fixed effects produces consistent estimators of the parameters of equation (2), whereas the random effects specification does not.

The cost we pay for using fixed effects estimation, as opposed to random effects, is that we cannot identify the coefficient of any explanatory variable that does not change over time. In this particular case, we are not able to directly estimate the effects of different vessel sizes on the jack mackerel catch. Nevertheless, the fixed effects specification does control for the size of each vessel because this is a variable that does not change over time. Therefore, the estimation of equation (2) does not suffer from an omitted variable bias due to the lack of explicit controls for vessel size.

As can be seen from the table, in Model (1) the coefficient of Biomass is slightly negative, but statistically not different from zero. A potential explanation for the non significance is that biomass may have no effect at all on jack mackerel catch. An alternative explanation is that the estimated coefficient of biomass could be biased. As it was discussed in section 4 , we believe there is an endogeneity problem that biases the estimated elasticity. 
Table 5-A: Annual Harvest Function

Dependent variable: $\ln$ (annual landed tonnage of jack mackerel)

\begin{tabular}{|c|c|c|c|c|}
\hline Variable & $\begin{array}{c}\text { Model } 1 \\
(O L S)\end{array}$ & $\begin{array}{c}\text { Model } 2 \\
\text { (I.V.) }\end{array}$ & $\begin{array}{c}\text { Model } 3 \\
\text { (I.V.) }\end{array}$ & $\begin{array}{c}\text { Model } 4 \\
\text { (I.V.) }\end{array}$ \\
\hline Constant & $\begin{array}{c}2.32 \\
(4.4732)\end{array}$ & $\begin{array}{c}35.42 \\
(8.1384)^{* *}\end{array}$ & $\begin{array}{c}38.9 \\
(6.5989)^{* *}\end{array}$ & $\begin{array}{c}39.16 \\
(7.399)^{* *}\end{array}$ \\
\hline Ln $\left(\right.$ Biomass $\left._{t}\right)$ & $\begin{array}{c}-0.04 \\
(0.2637)\end{array}$ & $\begin{array}{c}-1.99 \\
(0.4794)^{* *}\end{array}$ & $\begin{array}{c}-2.20 \\
(0.3895)^{* *}\end{array}$ & $\begin{array}{c}-2.21 \\
(0.4355)^{* *}\end{array}$ \\
\hline $\operatorname{Ln}\left(\right.$ Effort $\left._{\text {it }}\right)$ & $\begin{array}{c}1.07 \\
(0.0476)^{* *}\end{array}$ & $\begin{array}{c}1.06 \\
(0.0397)^{* *}\end{array}$ & $\begin{array}{c}1.06 \\
(0.4053)^{* *}\end{array}$ & $\begin{array}{c}1.06 \\
(0.0404)^{* *}\end{array}$ \\
\hline $\operatorname{Ln}\left(\mathrm{Age}_{\mathrm{it}}\right)$ & $\begin{array}{c}0.15 \\
(0.1056)^{*}\end{array}$ & $\begin{array}{c}0.12 \\
(0.0802)\end{array}$ & $\begin{array}{c}0.11 \\
(0.0789)\end{array}$ & $\begin{array}{c}0.11 \\
(0.0796)\end{array}$ \\
\hline Trend $_{t}$ & $\begin{array}{c}-0.17 \\
(0.0250)^{* *}\end{array}$ & $\begin{array}{c}-0.32 \\
(0.0394)^{* *}\end{array}$ & $\begin{array}{c}-0.34 \\
(0.0327)^{* *}\end{array}$ & $\begin{array}{c}-0.34 \\
(0.0357)^{* *}\end{array}$ \\
\hline Research98 & $\begin{array}{c}1.31 \\
(0.3259)^{*}\end{array}$ & $\begin{array}{c}1.29 \\
(0.5137)^{*}\end{array}$ & $\begin{array}{c}1.29 \\
(0.5179)^{*}\end{array}$ & $\begin{array}{c}1.29 \\
(0.5245)^{*}\end{array}$ \\
\hline Research99 & $\begin{array}{c}3.54 \\
(1.6336)^{*}\end{array}$ & $\begin{array}{c}3.56 \\
(1.6205)^{*}\end{array}$ & $\begin{array}{c}3.26 \\
(1.5492)^{*}\end{array}$ & $\begin{array}{c}3.56 \\
(1.6261)^{*}\end{array}$ \\
\hline Research2000 & $\begin{array}{c}2.15 \\
(0.5700)^{*}\end{array}$ & $\begin{array}{c}2.27 \\
(0.8054)^{*}\end{array}$ & $\begin{array}{c}2.28 \\
(0.8129)^{*}\end{array}$ & $\begin{array}{c}2.28 \\
(0.8522)^{*}\end{array}$ \\
\hline D2001 & $\begin{array}{c}0.82 \\
(0.1367)^{* *}\end{array}$ & $\begin{array}{c}1.22 \\
(0.1601)^{* *}\end{array}$ & $\begin{array}{c}1.27 \\
(0.1494)^{* *}\end{array}$ & $\begin{array}{c}1.27 \\
(0.1542)^{* *}\end{array}$ \\
\hline D2002 & $\begin{array}{c}0.42 \\
(0.1395)^{*}\end{array}$ & $\begin{array}{c}0.96 \\
(0.1833)^{* *}\end{array}$ & $\begin{array}{c}1.02 \\
(0.1637)^{* *}\end{array}$ & $\begin{array}{c}1.03 \\
(0.1718)^{* *}\end{array}$ \\
\hline Research98·ln $\left(\right.$ Effort $\left._{i t}\right)$ & $\begin{array}{c}-0.18 \\
(0.0410)^{*}\end{array}$ & $\begin{array}{c}-0.16 \\
(0.0652)^{*}\end{array}$ & $\begin{array}{c}-0.16 \\
(0.0651)^{*}\end{array}$ & $\begin{array}{c}-0.16 \\
(0.0665)^{*}\end{array}$ \\
\hline Research99·ln $\left(\right.$ Effort $\left._{i t}\right)$ & $\begin{array}{c}-0.52 \\
(0.2059)\end{array}$ & $\begin{array}{c}-0.51 \\
(0.2044)^{* *}\end{array}$ & $\begin{array}{c}-0.50 \\
(0.1949)^{* *}\end{array}$ & $\begin{array}{c}-0.50 \\
(0.2051)^{* *}\end{array}$ \\
\hline Research $2000 \cdot \ln \left(\right.$ Effort $\left._{i t}\right)$ & $\begin{array}{c}-0.26 \\
(0.0717)^{*} \\
\end{array}$ & $\begin{array}{c}-0.22 \\
(0.1017)^{*}\end{array}$ & $\begin{array}{c}-0.22 \\
(0.1031)^{*}\end{array}$ & $\begin{array}{c}-0.22 \\
(0.1077)^{*}\end{array}$ \\
\hline $\mathrm{R}^{2}$ & 0.8511 & 0.8526 & 0.8534 & 0.8529 \\
\hline $\mathrm{F}$ & 144.08 & 150.12 & 152.9 & 151.36 \\
\hline $\mathrm{N}$ & \multicolumn{4}{|c|}{2229} \\
\hline Number of Vessels & \multicolumn{4}{|c|}{283} \\
\hline Average Obs. Per Vessel & \multicolumn{4}{|c|}{7.9} \\
\hline Max Obs. Per Vessel & \multicolumn{4}{|c|}{18} \\
\hline Min Obs. Per Vessel & \multicolumn{4}{|c|}{1} \\
\hline
\end{tabular}


In fact, a Hausman test (Hausman 1978) rejects the exogeneity of the Biomass variable in the harvest function. Additionally, in the data we use there is measurement error in the biomass variable, which also biases the estimates. In the case of measurement error we know the direction of the bias: the estimated coefficient of the biomass will be biased toward zero due to attenuation bias (Greene 2003). However, the use of valid instrumental variables solves both problems and provides consistent estimates of the biomass elasticity.

Model (2) estimates the same equations as Model (1) but using Niño1 as instrument for Biomass. The coefficient of Biomass is now negative, fifty times larger in absolute value than in model 1 , and statistically significant. The estimated elasticity is -2 implying that, as average during the studied period, a one per cent increase in the jack mackerel biomass reduces the catch of individual vessels by two per cent.

As expected, effort has a positive and statistically significant impact on catch volume. An increase of one per cent in the number of annual hours a vessel is off-shore is associated with a one per cent increase in the catch of jack mackerel. Recall that estimated coefficients in our case represent average values across time and across vessel size categories.

The coefficient of the age variable is positive, but statistically not different from zero. We did not have a prior sign for this variable. The age of a vessel might capture its technological obsolescence, in which case the coefficient should be negative, and also some accumulated learning by doing effects, in which case the coefficient should be positive. Therefore, a zero coefficient can be explained either because these two effects offset each other or because vessel's age actually does not have any effect on catch. The data we have does not allow us to distinguish between the two alternatives.

The linear trend has a negative and significant coefficient. The negative sign obtained could be capturing the fact that catch productivity in this fishery has been declining over time; partly because fish resources have become scarcer (though the biomass variable is explicitly controlling for this effect) and also because traveling distance to productive fishing grounds has become longer over time. There might be perhaps some other explanations. But what it is important is that the trend variable is statistically significant and, therefore, cannot just be dropped from the regression. Still, and as an additional robustness check of the results, we also run the same regressions without the time trend and the results were not qualitatively different.

The 'Research Fishing Trips' (RFT) dummies are all positive and statistically significant. We also included in the regression the RFT dummies interacted with effort because vessels participating in the RFT program had to follow a pre-assigned fishing path specified by IFOP, 
additionally with complying with per vessel catch quotas when harvesting jack mackerel. Therefore, catch yields, targeted fishing grounds and fishing effort levels were all affected by vessel participation in the RFT program.

Evaluated at the mean value of the sample, the impact of participating in the RFT program was to increase at the margin the per vessel catch of jack mackerel by 0.1 per cent in 1998, reduce it by 0.3 per cent in 1999 and increase it by 0.6 per cent in 2000 . Regarding the catch-to-fishing effort elasticity, its value changes from 1.06 (during the years in which there was no research fishing trips) to 0.9 in $1998,0.55$ in 1999 and 0.84 in 2000. Therefore, participation in the RFT program made marginal fishing hours less productive, though the RFT program did increase per vessel average catch of jack mackerel (compared with per vessel average yields obtained during the years subject to 'Olympic race').

The dummies for the years 2000 and 2001 are also positive and significant, showing the positive impact that the introduction of individual catch quotas had on per vessel catch of jack mackerel. With individual catch quotas, companies were now able to fully optimize the operational use of their vessels over the year. As a result, not only the number of operating vessels did rapidly and significantly decline but also the operating fleet became increasingly concentrated on vessels belonging to the large size $\left(>801 \mathrm{~m}^{3}\right)$ category. Peña, Basch \& Vergara (2003) have shown that large sized vessels operating at the central southern pelagic fishery do obtain on average higher catch yields, per unit of fishing effort, when compared with smaller vessels.

Model (3) adds Niño1 with one year lag as instrument because an episode of 'El Niño' can affect the biomass not only through contemporary effects but also over a longer period of time, given the transmission of 'El Niño' effects through the biomass' age structure. The absolute value of the biomass coefficient is slightly larger than in Model (2) and again it is negative and statistically significant. The point elasticity is now -2.2. Model (4) adds an additional annual lag of Nino1 as another instrument for biomass, given that recruitment occurs at two years old in the Chilean jack mackerel stock. The point elasticity is again -2.2 and statistically significant.

Table 5-B reports the first-stage estimation results for the oceanic 'El Niño' variables which are used as instruments for biomass. Each of the three 'El Niño' variables consistently obtains a negative and statistically significant coefficient of impact upon biomass. According to model 4, the contemporaneous impact of the 'El Niño' in a given year $t$, upon the Chilean jack mackerel biomass, is nearly doubled by the cumulative biomass effects which are observed one and two years later (and which are transmitted through the biomass' age structure). 
Table 5-B: First-Stage Regressions

(fixed-effects estimation)

Dependent variable: $\operatorname{Ln}\left(\right.$ Biomass $\left._{\mathrm{t}}\right)$

\begin{tabular}{lccc}
\hline Variable & Model 2 & Model 3 & Model 4 \\
\hline Niño $1_{\mathrm{t}}$ & -0.098 & -0.097 & -0.103 \\
& $(0.0036)^{* *}$ & $(0.0033)^{* *}$ & $(0.0036)^{* *}$ \\
Niño $1_{\mathrm{t}-1}$ & & -0.046 & -0.046 \\
& & $(0.0042)^{* *}$ & $(0.0039)^{* *}$ \\
Niñol $1_{\mathrm{t}-2}$ & & -0.046 \\
$\mathrm{R}^{2}$ & & & $(0.0023)^{* *}$ \\
Test F & 0.944 & 0.947 & 0.949 \\
Test F (overid test) & 1704.66 & 2258.45 & 2408.95 \\
$(p$-value $)$ & & 0.29 & 0.57 \\
\hline
\end{tabular}

Values in parenthesis are robust (to heteroskedasticity and autocorrelation) standard errors. Due to space restrictions, only the coefficients and standard errors of the instruments are presented in the table. However, the first-stage regressions also included all the exogenous variables in the model.

**: significant at $99 \%$ confidence.

The negative coefficient estimated for the 'El Niño' effects on jack mackerel biomass is consistent with recent testing (Yepes 2004) of the 'El Niño' effects upon the recruitment rate (number of recruits as proportion of the spawning biomass) of the Chilean jack mackerel stock. Yepes (2004) reports a negative and statistically significant coefficient of impact, of a dichotomic (and oceanic) measure of the 'El Niño', upon the recruitment rate of the Chilean jack mackerel stock.

Studies about other small shoaling pelagic fish have also reported a negative relationship between fish biomass and the occurrence of 'El Niño' phenomenon. Csirke $(1980,1988)$ describes a relationship of this type for the Peruvian anchovy. Quoting from Csirke (1988, p. 2867):

“...during the onset of the 1972-73 'El Niño' phenomenon in the Southeast Pacific, the northern and central stock of the Peruvian anchovy was compressed inshore and further south by the advance of the warm water front that reduced the area with water temperatures suitable for the anchovy shoals....This contributed to an increase in the catchability coefficient, ... while the recruitment (the main element of the natural productivity of the stock) was also sharply reduced." (Italics are ours).

Regarding the collapse of the Californian sardine fishery in the early 1950s, Cushing (1988, pp. 253) and Herrick et al. (2004) also quote different studies (for example, Marr 1960; Baumgartner et al. 2002; McFarlane et al. 2002; Chavez et al. 2003) which suggest a negative relationship between sardine recruitment success and environmental shocks. ${ }^{17}$ 
Table 6: Estimated catch-input Elasticities, Confidence Intervals (at 95\%)

\begin{tabular}{lcccc}
\hline \multicolumn{1}{c}{ Variable } & Model 1 & Model 2 & Model 3 & Model 4 \\
\hline Biomass $_{\mathrm{t}}$ & $-0.56 ; 0.48$ & $-2.93 ;-1.05$ & $-2.97 ;-1.44$ & $-3.02 ;-1.41$ \\
Effort $_{\mathrm{it}}$ & $0.98 ; 1.17$ & $0.98 ; 1.14$ & $0.98 ; 1.14$ & $0.99 ; 1.14$ \\
Age $_{\text {it }}$ & $-0.05 ; 0.36$ & $-0.04 ; 0.28$ & $-0.04 ; 0.27$ & $-0.04 ; 0.27$ \\
\hline
\end{tabular}

Table 6 reports the confidence intervals of the estimated catch-input elasticities for all models. The elasticities of effort and age do not vary much across models. In the case of effort, the elasticity is positive on the whole interval and it ranges between 0.98 and 1.17. In the case of age, an elasticity of zero falls within the interval which ranges between -0.05 and 0.36 .

The confidence interval for the biomass elasticity includes zero and ranges between -0.56 and 0.48 when estimated with a fixed effects model without solving the endogeneity and measurement error biases. Once the latter two biases are eliminated with the use of instrumental variables, the confidence interval for the biomass elasticity only includes values which are consistently negative over the whole range. Therefore, the endogeneity of the biomass variable biases upwardly the magnitude of its coefficient in the Cobb-Douglas harvest function. In the case of our data, the endogeneity problem can even change the sign of the catch-to-biomass coefficient.

As it usually happens when using instrumental variables, the results hinge on the assumption about the instruments not being correlated with the error term in the harvest function. This assumption cannot be tested. However, when more instruments than needed to identify an equation are available, it is possible to test whether the additional instruments are valid in the sense that they are uncorrelated with the error term in the structural equation. The last row of Table 5-B shows the results of testing these overidentifying restrictions. As it can be seen from the table, in all cases we cannot reject, at any reasonable confidence level, the null hypothesis that the instruments are valid.

Once we have corrected the endogeneity problem, why do we obtain a negative value for the catch-to-biomass coefficient? Different underlying biological and ecosystem mechanisms could be cited. Some of these refer to density-dependent processes related to changes in biomass abundance and its spatial and seasonal distribution, involving effects upon natural growth, mortality as well as recruitment rates. Other mechanisms refer to density-independent effects of 
environmental shocks; for example, changes in availability of adequate food or temperature related changes in somatic growth.

Whatever be the specific combination of underlying mechanisms, the negative relationship found between per vessel catch and biomass level should be reflecting the effect of a negative relationship between the catchability coefficient (denote it by $q$ ) and the biomass level. The catchability coefficient is defined as $q_{t}=\left(H_{t} / E_{t}\right) / B_{t}$, where $H_{t}$ is the catch in period $\mathrm{t}, E$ the fishing effort and $B$ the fish biomass. Csirke (1988, p. 289) cites studies for different pelagic fisheries where the estimated values for $q$ vary inversely with $B$.

In the case of a Cobb-Douglas harvesting function that includes fish biomass as one of its regressors, and considering a relationship such as $q=a B^{\gamma}$, a negative value of $\gamma$ would imply, all the rest being constant, a lower estimated value for the biomass coefficient (versus the case of $\gamma$ being non negative). Related to the possibility of $\gamma$ being negative in the case of pelagic fish, a frequently cited hypothesis is that when fish abundance falls, the stock reduces the range of its feeding and breeding areas, with concurrent decreases in the number of schools, though the average size of each school tends to remain constant. In this case, the fish stock reduces the range of its spatial distribution while simultaneously increasing its density. The expected result is an increase in catch yields per unit of fishing effort. As Csirke (1988, p. 274) has described it: "if the (pelagic) stock is falling, the true fishing mortality may stay high, or even increase."

Another example of an hypothesis related to pelagic fish, specifically to the Pacific sardine, and which also helps illustrate the possibility of $q$ being inversely related to $B$, though now referring to effects triggered by changes in sea temperature, can be cited from Clark and Marr (1955). These authors suggested that schools of sardine may become denser and contain more fish at lower water temperatures than they do at higher temperatures, implying that catch might indeed increase with a decline in water temperature (while the latter change also produces a fall in sardine biomass).

Regarding the case of the Chilean jack mackerel stock, we are not aware of conclusive scientific knowledge that could help explain the specific nature of underlying biological and/or ecosystem mechanisms as those referred to in the previous paragraphs. Nonetheless, it is clear that some important changes have indeed occurred during the studied period.

On the one hand, biomass availability has monotonically declined, and in a significant proportion, since the early 1990s. At year 2002 total biomass was only 40 per cent of its peak estimated levels during the second half of the 1980s (see Table 1). ${ }^{18}$ On the other hand, and 
particularly since the occurrence of the 1997-98 'El Niño' episode (which was the 'El Niño' of

greatest intensity to have occurred during the $20^{\text {th }}$ century), there has been increasing evidence that the Chilean jack mackerel stock has moved southwards its spatial distribution (Barria et al. 2002) and further into open seas ${ }^{19}$, particularly since 2000-2001 (Subpesca 2004). As a consequence, the Chilean industrial fleet has been extending its areas of fishing operations (since the early 2000s) up to $600-700 \mathrm{~nm}$.

\section{Concluding remarks}

The results presented in this paper suggest that biomass endogeneity could be a relevant problem when biomass VPA estimates are used as explanatory variable in a yearly harvest function. In the specific case of the available data for the Chilean jack mackerel, we also faced a measurement error in the biomass variable, which biases towards zero (attenuation bias) the estimate of the biomass coefficient. Therefore, an OLS estimation of the harvest function produces inconsistent estimates of its coefficients.

As a matter of fact, when a Cobb Douglas harvest function was estimated by OLS, but without correcting for endogeneity and measurement error problems, we obtained a positive (though not significant) coefficient for biomass. Once the endogeneity and attenuation biases were dealt with by using instrumental variables, the biomass elasticity became persistently negative and statistically significant. It is important to highlight that these coefficients, estimated by fixed effects while simultaneously using valid instrumental variables, are consistent. Additionally, the standard errors, estimated by using the asymptotic variance matrix estimator proposed by Arellano (op.cit.), are robust to heteroskedasticity and autocorrelation. Therefore, as long as the Niño1 variables are valid instruments for jack mackerel biomass, the endogeneity of the VPA biomass variable biases upwardly the magnitude of its coefficient in a Cobb-Douglas harvest function. In the case of our data, the endogeneity problem even changes the sign of the catch-to-biomass elasticity.

The negative biomass elasticity could be potentially explained by different underlying biological and ecosystem mechanisms, some of which are density-dependent processes related to changes in biomass abundance and its spatial and seasonal distribution; while others correspond to density-independent effects of environmental shocks. However, as it is always the case when using instrumental variables, the negative estimated coefficient for biomass could instead be the result of using invalid instruments. Nonetheless, in the case of overidentifying instruments we do 
not reject that the instruments we used are valid. Even though, it would be important to explore the use of alternative valid instruments to confirm our results.

A second contribution of the paper is related to the effects of 'El Niño' phenomenon on the jack mackerel biomass. The results show that an oceanic 'El Niño' episode not only has negative effects on contemporaneous jack mackerel biomass but also negative biomass effects which last for at least two additional years. The latter is related to transmission over time of 'El Niño' effects through biomass' age structure. Specifically, due to the 'El Niño' effects on the rate of survival of eggs and larvae, a proportion of which will become (after a two year period) the new recruitment cohort.

It is known that during the studied period jack mackerel biomass had important changes. Not only its abundance declined significantly and monotonically, since the early 1990s, but also there is evidence that changes in the stock's spatial distribution occurred, particularly since the early 2000s. Some of these changes may be related to 'El Niño' episodes. However, there is no robust scientific knowledge about these matters yet.

Therefore, a clear resulting message is that, in order to enhance understanding about the relationship between fish biomass and catch yields in the fishery analysed, there is still lack of scientific knowledge about the biology of jack mackerel stocks. It seems particularly relevant to improve understanding of 'El Niño' effects upon jack mackerel biomass and spatial aspects which affect the relationship between fish abundance and catch yields. For example, triggered changes in the spatial distribution of jack mackerel's food stocks, as a result of 'El Niño' episodes; as well as resulting changes in the range of the fish stock's feeding and breeding areas. Further research should also be directed to analyse multi-species interactions; for example, regarding the hypothesis of squid's (Dosidicus gigas) predation on the Chilean jack mackerel stock.

Going beyond the specific case of the fishery analysed in this paper, changes in environmental conditions can produce adjustments in fish stock's spatial distribution, triggering in turn changes in fishing effort's and catch's spatial distribution. Related to these processes of spatial change and adjustment, it is worth recalling that both Ricker (1958) and Gulland (1969) did already recommend, for purposes of stock assessment methodologies, the stratification of catch and effort data by geographical areas. It would seem to be equally relevant trying to follow their advice when the main objective consists in studying the relationship between fish biomass and catch yields. 


\section{References}

Arellano, M. (1987), “Computing Robust Standard Errors for Within Groups Estimators', Oxford Bulletin of Economics and Statistics, 49 (4), pp. 431-434.

Barría, P., A. Aranís, S. Mora, G. Böhm, R. Serra, C. Martínez, V. Catasti, H. Reyes, G. Muñoz y A. Gómez (2002), “Diagnóstico de la Pesquería Chilena de Jurel”, in E. Yañez (ed.), Actividad Pesquera y de Acuicultura en Chile, Valparaíso: Escuela de Ciencias del Mar, UCV, pp. 123-141.

Basmann, R. L. (1960), “On Finite Sample Distributions of Generalized Classical Linear Identifiability Test Statistics”, Journal of the American Statistical Association, 55 (292), pp. 650-59.

Baumgartner, T., A. Soutar and V. Ferriera-Bartrina (2002), "Reconstruction of the History of Pacific Sardine and Northern Anchovy Populations Over the Past Two Millennia from Sediments of the Santa Barbara Basin, California”, CalCOFI Rep., 33, pp. 24-40.

Bjorndal, T. and J. Conrad. (1987), “The Dynamics of an Open Access Fishery”, Canadian Journal of Economics, 20 (1), pp. 74-85.

Bjorndal, T. (1988), "The Optimal Management of North Sea Herring”, J. of Environmental Economics and Management, 15 (1), pp. 9-29.

Bjorndal, T. (1989), "Production in a Schooling Fishery: The case of the North Sea Herring Fishery", Land Economics, 65, pp. 49-56.

Bjorndal, T., J. Conrad and K. G. Salvanes (1993), "Stock Size, Harvesting Costs, and the Potential for Extinction: the case of Sealing", Land Economics, 69 (2), pp. 156-67.

Chavez, F.P., J. Ryan, S.E. Lluch-Cota and M. Ñiquen (2003), "From Anchovies to Sardines and Back: Multidecadal Change in the Pacific Ocean”, Science, 299 (5604), pp. 217-221.

Clark, C. (1976), Mathematical Bioeconomics. The Optimal Management of Renewable Resources, New York: John Wiley \& Sons.

Clark, C. (1982), "Concentration Profiles and the Production and Management of Marine Fisheries", in W. Eichhorn, R. Henn, K. Neumann, and R.W. Shepard, (eds.), Economic Theory of Natural Resources, Würzburg, Germany: Physica-Verlag.

Clark, F.N. and J.C. Marr (1955), "Population Dynamics of the Pacific Sardine", CalCOFI Prog. Rep. 1 July 1953 - 31 March 1955, pp. 11-48. 
Crone-Bilger, C. (1990), International and Economic Policy Aspects of the Soviet Ocean-going Fishing Industry, Ph.D. Thesis in Economics, University of London, UK.

Csirke, J. (1988), "Small Shoaling Pelagic Fish Stocks", in J. A. Gulland (ed.), Fish Population Dynamics. The Implications for Management ( $2^{\text {nd }}$ edition), Chichester, UK: John Wiley \& Sons., pp. 271-302.

Csirke, J. (1980), "Recruitment in the Peruvian Anchovy and its Dependence on the Adult Population”, Rapp. Proces-Verb. Réun. Cons. Int. Explor. Mer, 177, pp. 307-13.

Cubillos, L. (ed.) (2003), “Condición Biológica del Jurel en Alta Mar, año 2001”, Informe Final, Proyecto FIP \# 2001-12, Valparaíso: Subsecretaría de Pesca.

Cushing, D.H. (1988), The Provident Sea, Cambridge, UK: Cambridge University Press.

Elizarov, A.A., A.S. Grechina, B.N. Kotenev, and A.N. Kuzetsov (1993), "Peruvian Jack Mackerel, Trachurus symmetricus murphyi, in the Open Waters of the South Pacific9, J. Ichth., 33 (3), pp. 86-104.

Evseenko, S.A. (1987), "Reproduction of the Peruvian Jack Mackerel, Trachurus symmetricus murphyi, in the Southern Pacific", J. Ichth. 27 (3), pp. 151-160.

Greene, W. (2003), Econometric Analysis, (5 ${ }^{\text {th }}$ Edition): Prentice Hall.

Griliches, Z. and J. Hausman (1986), "Errors in Variables in Panel Data", Journal of Econometrics, 31(1), pp. 93-118.

Gulland, J. A. (1969), "Manual of Methods for Fish Stock Assessment. Part 1. Fish. Pap., FAO Manuals in Fisheries Science, FRS/M4, pp. 154.

Hannesson, R. (1983), "Bioeconomic Production Function in Fisheries: Theoretical and Empirical Analysis", Canadian Journal of Fisheries and Aquatic Sciences, 40, pp. 968982.

Hausman, J.A. (1978), "Specification Tests in Econometrics", Econometrica, 46 (6), pp. 1251 1271.

Herrick, S.F., K. Hill and C. Reiss (2004), “An Optimal Harvest Policy for the Recently Renewed United States Pacific Sardine Fishery", paper presented at the GLOBEC-SPACC Workshop on the Economics of small pelagics and climate change, September, University of Portsmouth, UK. 
Imbens, G. and D. Hyslop (2001), "Bias from Classical and Other Forms of Measurement Error”, Journal of Business and Economic Statistics, 19 (4), pp. 141-149.

McFarlane, G.A., P.E. Smith, T.R. Baumgartner and J.R. Hunter (2002), “Climate Variability and the Pacific Sardine Populations and Fisheries", American Fishery Society Symposium, 32, pp. 195-214.

Marr, J. C. (1960), "The Causes of Major Variations in the Catch of Pacific Sardine (Sardinops Caerulea Girard)", World Sci. meeting on the biology of sardines, 3, pp. 1-69, FAO, Rome.

Opsomer, J. D. and J. Conrad (1994), “An Open Access Analysis of the Northern Anchovy Fishery", J. of Environmental Economics and Management, 27 (1), pp. 21-37.

Peña-Torres, J., S. Vergara and M. Basch (2004), "El Dilema de la Escala Productiva frente a Ciclos de Abundancia: La Pesca Industrial en Chile”, El Trimestre Económico 71 (283), pp. 575-612.

Peña-Torres, J., M. Basch and S. Vergara (2003), "Eficiencia Técnica y Escalas de Operación en Pesca Pelágica: un análisis de fronteras estocásticas”, Cuadernos de Economía 40 (119), pp. $43-83$.

Peña-Torres, J. (2002), “Debates sobre Cuotas Individuales Transferibles: ¿Privatizando el Mar? ¿Subsidios? o ¿Muerte Anunciada de la Pesca Extractiva en Chile?”, Estudios Públicos, 86 (May), pp. 183- 222.

Peña-Torres, J., R. Serra \& M. Basch (2000), "Who can Fish What and Where: Chile"s Tradeoffs in High Seas Fishing of Transboundary Species", Marine Resource Economics, 14 (3), pp. 245-262.

Peña-Torres, J. (1997), “The Political Economy of Fishing Regulation: the case of Chile”, Marine Resource Economics, 12 (4), pp. 239- 248.

Quinn II, T.J. and R.B. Deriso (1999), Quantitative Fish Dynamics, Oxford: Oxford University Press.

Ricker, W.E. (1958), "Handbook of Computations for Biological Statistics of Fish Populations, Can. Fish. Res. Bd. Bull., 119, pp. 1-300.

Sargan, J. D. (1958), “The Estimation of Economic Relationships Using Instrumental Variables”, Econometrica, 26 (3), pp. 393-415. 
Serra, R. (1991), "Important Life History Aspects of the Chilean Jack Mackerel (Trachurus symmetricus murphyi)", Investigación Pesquera (Chile), 36, pp. 67-83.

Serra, R. y C. Canales (2002), “Investigación Captura Total Permisible Jurel, 2003”, Informe Final, IFOP-SUBPESCA, pp. 48. Valparaíso, Chile.

SUBPESCA (2004), “Cuota Global Anual de Captura de Jurel, año 2005”, Informe Técnico \#79/2004, Octubre: Subsecretaría de Pesca, Valparaíso.

Wooldridge, J. M. (2002), Econometric Analysis of Cross Section and Panel Data. Cambridge, MA: MIT Press.

Yepes, M. (2004), "Dinámica Poblacional del Jurel: Reclutamiento asociado a Factores Ambientales y sus Efectos sobre la Captura". Tesis, Master of Arts in Economics, Georgetown University-ILADES Programme: Universidad Alberto Hurtado, Santiago, Chile.

\footnotetext{
${ }^{*}$ We gratefully acknowledge access to data provided by Subsecretaría de Pesca and the Chilean Institute of Fisheries Research (IFOP). We also thank biological information and comments received from marine biologists Patricio Barria and Rodolfo Serra, both staff at IFOP. Remaining errors are the authors' own responsibility.

${ }^{1}$ Peña et al. $(2003,2004)$ replace the contemporaneous value of fish biomass by its one year lagged value, as a partial solution to contemporaneous correlation between the biomass variable and the residual term of the catch equation. Nonetheless, this strategy does not solve in a totally convincing way the issue of biomass endogeneity, as contemporaneous catch data is used to estimate current as well as past biomass values, when VPA stock assessment methodology is involved.

${ }^{2}$ From the point of view of Government administration, Chile is divided into twelve regions.

${ }^{3}$ There are two main competing hypotheses in this debate: a 'single stock' (Elisarov et al., 1993) versus a 'three stocks' theory. Serra (1991) supports the theory of three independent stocks (Chilean, Oceanic, and Peruvian).

${ }^{4}$ Fishing operations did occur 210 to 250 miles off the Chilean coast. During the late 1980 s, this fleet was composed of about 70 factory mid-water trawlers. In 1990 they caught about 1.1 million tons of jack mackerel in adjacent high seas waters in the Southeast Pacific. Retreat from this fishery in 1992 was an
} 
economic consequence of the disintegration of the ex Soviet Union (Crone-Bilger, 1990, p. 118). During 2002-2005, renewed fishing operations by trawlers belonging to foreign fleets have been observed in these high seas areas. This includes fishing operations by Chinese, Korean and Russian fleets. According to Chinese Government's official statements, during 2002-2005 the Chinese fleet would have harvested between 76-120 thousand annual tons of jack mackerel (El Mercurio, 16/09/03 and 20/05/04). See also Peña-Torres et al. (2000). Chilean fishing companies have quoted an estimate of 250 thousand tons as the total jack mackerel catch obtained by foreign fleets in 2004 (El Mercurio, 22/03/05).

${ }^{5}$ Considering the period $1985-97$, i.e. before biological closures started to be used in the jack mackerel fishery, jack mackerel represented on average 88 per cent of total industrial landings in the central-southern region. The industrial catch of the three main harvested species fluctuated between 86 per cent and 98 per cent of total landings during 1985-2002.

${ }^{6}$ Because of its emphasis on data sampling collection, the RFT Program imposed restrictions on the technical characteristics of participating vessels. Additionally, each of the latter had to carry on-board a technical observer. In practice, a dominant proportion of the participating vessels belonged to the 'large' $\left(>800 \mathrm{~m}^{3}\right)$ vessel-size category. For example, during 1999 a total of 127 ships did participate at the RFT program for the jack mackerel fishery. Of that total, 70 belonged to the 'large' size category, 50 to the 'medium' size (301-800 $\left.\mathrm{m}^{3}\right)$ group and only 7 to the 'small' $\left(80-300 \mathrm{~m}^{3}\right)$ size category.

${ }^{7}$ A fishery unit is composed of a particular fish species and a specific marine area.

${ }^{8}$ Table 1 (columns 2 and 3) conceals the real (very fast) speed of the operational adjustments that were (immediately) triggered by the introduction, since February 2001, of individual catch quotas into this fishery. The reason for this is that during January 2001 the industrial fleet did operate under the so-called 'Olympic race' incentives. Hence, yearly statistics over-report the average monthly number of operating fishing vessels during the remaining of that year.

9 Regarding the fishery under analysis, estimations of the harvest technology which consider a more general (Translog) functional form can be found at Peña-Torres et al. (2004 and 2003).

${ }^{10}$ IFOP is a governmental institution whose mission is to provide scientific information as the basis for fisheries regulation and the preservation of marine resources. 
${ }^{11}$ Catch is the dependent variable in the regressions. Therefore, its measurement error (given the use of per vessel landings) is captured by the error term of the regression. However, this measurement error does not affect the properties of the estimators.

12 During the 1998-2000 period only a limited number of the purse seiners operating at the central-southern pelagic fishery was allowed to fish jack mackerel. A predominant proportion of the favoured vessels belonged to the large sized category. As a result, we observe a generalised fall in the share of jack mackerel landings, but with particular intensity in the vessel size categories below $800 \mathrm{~m}^{3}$.

13 In practice, a non trivial proportion of this industrial fleet's fishing trips are species specialised. This is related to the specific areas and fishing seasons in which vessels operate.

14 Jack mackerel annual biomasses are estimated by IFOP on the basis of catch data sampling that is gathered by prospecting areas between 0-200 nautical miles and from $33^{0}$ up to $40^{\circ} \mathrm{SL}$.

15 During the 1998-2000 period, the RFT Program implied a de facto use of TACs, though only for jack mackerel; while the other pelagic species remained under closed entry but common property conditions.

${ }^{16}$ The sea surface temperature is measured at a region known as Niño 3.4 (120W-170W, 5N-5S), located in the East Central Equatorial Pacific region.

${ }^{17}$ Quoting from Chavez et al. (2003, p. 217), “The sardine and anchovy fluctuations are associated with large-scale changes in ocean temperatures; for 25 years, the Pacific is warmer than average (the warm, sardine regime) and then switches to cooler than average for the next 25 years (the cool, anchovy regime)." ${ }^{18}$ IFOP (Subpesca, 2004) has estimated that jack mackerel spawning biomass at year 2004 was slightly above 4 mills tons.

${ }^{19}$ Hydro-acoustic biomass surveys, performed by IFOP during May-June of years 2003-2004, have found high concentrations of jack mackerel (especially of younger cohorts of the adult stock) in the 200-400 nm region of the total surveyed area (which also includes the $5-200 \mathrm{~nm}$ region, starting from $33^{0}$ and covering up to $42^{0} \mathrm{SL}$ ). An hypothesis which has been suggested as contributing explanation for the change in the spatial distribution of the Chilean jack mackerel stock refers to the (cyclical) occurrence of a highabundance pulse of squid (Dosidicus gigas), a cephalopod which has been massively observed in the central-southern fishing grounds of Chile since 2002-2003. 